\title{
Life Universe, Universe Body and Something from
}

\section{Nothing}

\author{
Yan Jinzhong $^{1}$ and Yan Zhangxi ${ }^{2}$ \\ 1. Changsha Jiageer Machinery Manufacturing Co., Ltd., Pingtang Town, Changsha City, Hunan 410208, China \\ 2. Beijing Didi Infinite Technology Development Co., Ltd., Beijing 100086, China
}

\begin{abstract}
Universe life includes the universe realm, the life realm, human society and man-made materials. Each life has four grades There are four different "me" in each life: true me, Yang me, Yin me and conscious me. True me never dies while Yang me, Yin me and conscious me all appear and go. The heart of life is also a system consisting of four grades (true heart + Yang me heart + Yin me heart + conscious heart). Life is a four-seasonal whole dominated by heart. True me is true while Yang me, Yin me and conscious me are false. The general law of the universe is an operating body of general rules. Both the operating body of general rules and the life body are combination of the true and the false. The operating body of general rules is a body with two aspects and the combination and an autonomous operation of movement with stillness, gathering with parting and rising with falling. The operating body of general rules dominated by true me is the universe body. The essential features of the universe body include: 1) it is empty; 2) it is absolutely quiet; 3) it exists forever; 4) it contains seeds for everything; 5) it generates everything in the universe; 6) it is solid and will never break; 7) its power is King Kong power. The zero-state of the galaxy is its basic state and the giant blank zone of the universe. The galaxy's turning from zero-state into one-state is getting something from nothing. The operating of general rule is presented as the four-seasonal movement or metabolism of life. It is a continuity of movement and stillness (life and death) and a process of something interacting with nothing. The modes of reproduction of life consist of self-generation, generation by augmentation and generation by transformation. The Milky Way Galaxy, the solar system and the earth are inorganic life with reproductive system and reproductive capacity. In the positive-going evolution, their inner morality power gradually decreases and undergoes different states and structures. Internal intercourse generates different lives. In the early days of the earth, the temperature was high and inorganic lives first appeared: humans, animals, plants and bacteria. When the temperature dropped to a proper degree, organic lives then appeared: bacteria, plants, animals and humans. Now, new lives are still appearing on the earth.
\end{abstract}

Key words: Life universe, true me, false me, universe body, something from nothing, something interacting with nothing.

\section{Introduction}

Everything in the universe is alive and the universe is a life. This is a common sense of all the religions in the world. Religions began over 2,000 years ago. They did not begin at random but were the result of self-improvement and internal requirement [1]. In this practice of self-improving, Buddhism, Taoism and Confucianism in the east have all reached the peak of the science of universe life, finding and proving the true features of the universe and humans and solving the ultimate problems such as the origins of the universe and life and which places humans come from

Corresponding author: Yan Jinzhong, Senior Engineer, research field: disciplinary sciences. and head for.

Buddhism and Taoism are science of internal need and a heaven-human integration universe life science and thinking science. When the science of external need - modern science - entered the time of life science and technology, it could then connect with Buddhism and Taoism [2]. The author has found the bridges connecting modern science with Buddhism and Taoism, namely, the four-seasonal theory [3] and the state space-time theory $[4,5]$, and has established new sciences; they are the science of broad universe life and the science of thinking [6].

The universe is life and has thinking, which is the precondition to explore the universe body. By cultivating their moral characters, wise men in the east 
have witnessed the body of the universe and given it very clear descriptions. For example, Sankara, a philosopher of the Middle Ages in India, once said that the superior Brahma is the origin and dependence of everything in the universe and all phenomena in the world come from Brahma. Brahma is united, permanent and pure. There is nothing different between the inner part and the outer part and it has no features, movement and change. Brahma goes beyond the subjective and objective concepts and goes beyond time, space, solidity, cause-effect and other categories we have experienced. It cannot be seen, smelled, touched and described but yet incredibly exists [7]. Brahma is "nothing", is the universe itself. Nothing is not nothing but everything.

Modern scientists are also study the universe body and "something from nothing". Of all the theories the most famous ones are the Big Bang Theory and the String Theory. But the basic fact is that neither of them can solve any problem. Both of them treat the super complex life universe as a simple substance, which is very ridiculous.

As for "something from nothing", the most well-known statement comes from Lao $\mathrm{Zi}$. In his Tao Te Ching, he said, "Everything in the universe comes from something, and something comes from nothing", which means "something interacting with nothing" [8]. Lao $\mathrm{Zi}$ based his "something from nothing" on the science of internal need rather than that of external science and on intangible life science rather than tangible substance science.

Since Buddhism, Taoism and Confucianism have

Table 1 Grades of the universe realm and life realm.

\begin{tabular}{lll}
\hline Four worlds [4, 5] & Universe realm & Life realm [10] \\
\hline 0-dimension world & Ontology galaxy & Buddhist pure realm \\
1-dimension world & Quasar & Colorless realm \\
2-dimension world & Elliptical galaxy & Color realm \\
& & Desire realm heaven \\
& & Asuras \\
3-dimension world & Whirlpool galaxy & Humans \\
& & Animals, plants, eukaryotes and prokaryotes \\
& & Hungry ghosts \\
\hline
\end{tabular}

known the secret of the universe's "something from nothing", we can see the original truth of the universe body and solve the mystery of "something from nothing" by studying the tangible and intangible science of life and the general law of the universe [9].

Modern science has brought humans to the darkest time in history, when there are more and more disasters and humans will encounter destruction at any time. In this darkest time, the only way out lies in solving the secret of the universe, telling humans the truth of life, turning the degraded modern science to upgraded morality science and making humans turning around to do good turns as soon as possible.

\section{Types and Grades of Universe Life}

\subsection{Types of Universe Life}

Universe life includes 1) universe realm (the earth, the solar system, stardust, the Milky Way galaxy, cluster of galaxies, super cluster of galaxies, super giant cluster of galaxies and the general universe), mountains, rivers and land, and flowers, grass and trees; 2) life realm: including the living life realm; 3) human society; 4) man-made materials and man-made life.

\subsection{Grades of Universe Life}

The universe realm and the life realm have different grades respectively (Table 1 ). Human society and the man-made world also have zero-dimension, one-dimension, two-dimension and three-dimension [6].

In the universe, zero-dimension life never appears Hell 
and goes but life in other realms appears and goes. Buddhism calls heaven humans (colorless realm, color realm, desire realm heaven), asuras, humans, animals, hungry ghosts and hell six realms of existence, of which heaven humans, asuras and humans are three good realms and animals, hungry ghosts and hell are three evil realms [11].

\subsection{Rigid Life and Elastic Life, Emotionless Life and Emotional Life}

\subsubsection{Rigid Life or Emotionless Life}

The life that strictly obeys the rules of nature is rigid life or emotionless life. The universe galaxy, mountains, rivers and land, flowers, grass and trees all belong to rigid life or emotionless life. They have no thought or desire. They appear when they should appear and disappear when they should disappear and obey general laws. Thus, they exist forever.

\subsubsection{Elastic Life and Emotional Life}

The life that sometimes obeys and sometimes violates the rules of nature is elastic life or emotional life. Lives in the three realms (colorless realm, color realm and desire realm) including humans and many animals belong to elastic life or emotional life. They have thoughts and desires and often deviate from the general laws to cycle among the six realms of existence.

\subsection{Tangible Life and Intangible Life}

The life that exists in tangible forms is tangible life, such as galaxies, living things and man-made life. But tangible life also includes the intangible nervous system, such as the nervous system of humans and the software system of robots.

Intangible life refers to the life that modern science cannot see and has no substance form. It includes Buddhism, colorless realm, color realm and hungry ghost and hell in the three evil realms.

\section{Four Different Grades of "Me" in the Life Body and the Heart System of Life}

\subsection{Four Different Grades of "Me" in the Life Body}

In human body, there are four different grades of "me" and four different "heart" $[12,13]$ (Table 2).

Of the four "me", true me never dies, which is the basis of immortal souls. The other grades of "me" come and go, thus called false me in Buddhism. When life states change, so will "me", the dominant power of life and the heart, and so will the thought.

\subsection{Different Forms of Life Are Dominated by Different Grades of "Me", or, Different Hearts}

1) Lives in the life realm are dominated by different grades of "me". Some of the lives in the life realm strictly obey the general rules but others deviate from them. This is caused by the fact that different lives are dominated by different dominators. For example, three-dimension humans are dominated by fallacious me with other grades of "me" assisting or hidden. Three-dimension humans always deviate from the general rules. The present humans are three-dimension humans, who severely deviate from the general rules. However, the zero-dimension humans - Buddhism - are dominated by true me. Other grades of "me" are hidden. The zero-dimension humans are rigid life that strictly obeys the general rules.

2) Galaxy life is dominated by true me. Galaxies are rigid life without thought or desire and follow the middle course. Galaxies are dominated by true me. The

Table 2 The four grades of "me" in life body.

\begin{tabular}{|l|l|l|}
\hline Different grades of "me" in life body & Different states of heart & Hidden "me" \\
\hline True me & True heart & Yang me, Yin me, fallacious me \\
\hline Yang me & Yang me heart & True me, Yin me, fallacious me \\
\hline Yin me & Yin me heart & True me, Yang me, fallacious me \\
\hline Fallacious me (conscious me) & Conscious heart & True me, Yang me, Yin me \\
\hline
\end{tabular}


other grades of "me", including conscious me, Yin me and Yang me integrate with true me.

\subsection{Substances Also Contain "Me"}

The universe is a life and all substances are life substances. Substances are born with lives and are dominated by the general laws of the universe. Therefore, all substances contain four different grades of "me". The feature of substances" "me" is that their four grades of "me" are all hidden. Substances cannot dominate themselves and cannot exist independently without life.

In this way, four states exist in everything in the universe in an integrated hidden state.

\subsection{The Heart System of Life}

From Table 2, we can see life's heart is a system formed by four grades of heart: true heart + fallacious heart (Yang me heart + Yin me heart + conscious heart). True heart and fallacious heart (false heart) form an integration and cannot be separated. True heart is the body and fallacious heart is use.

Heart is the soul system [12] of life. Without soul, life will not exist. Without soul, there will be no body, no thought, no society, country or man-made world. Without soul and thought, there will be no universe galaxies or various substances. Modern science does not study soul and cannot understand the function of heart.

\subsection{Life Is A Four-Seasonal Integration Dominated by} Heart

Life is a four-seasonal whole [3]. The dominator of life is heart, so life is a four-seasonal integration dominated by heart (true heart + fallacious heart).

\section{The Operating Body of General Rules Dominated by True Me Is the Universe Body}

\subsection{True and False Substances}

Taoism, Buddhism and Confucianism think that the things that can exist forever, have no birth or death and are not be dominated by the four-seasonal rules are truth. On the contrary, the things that have birth and death, and are dominated by the four-seasonal rules are falsehood. The substance phenomena, the spirit phenomena and the natural phenomena are not truth because they all have birth and death. The immortal pure land that religions pursue is the truth of the universe. Most humans on the earth have a life of only decades. This is a short existence and falsehood.

\subsection{The Dominator of Everything: Operating Chart of General Rules}

The general laws of the universe [9] can be transformed into the operating chart of general rules.

The operating chart of general rules originates from Taoism and Buddhism. According to Tao Te Ching, "Tao generates one; one generates two; two generates three and three generates everything" and "human is subject to the earth; the earth is subject to heaven; heaven is subject to Tao, and Tao is subject to nature" [8]. According to Buddhism, the evolution process of the universe is: positive: the universe body - colorless realm - color realm - desire realm and reverse: desire realm - color realm - colorless realm - Buddhism pureness realm [14]. Everything in the universe is subject to the general rules and dominated by it [9]. The operating chart of general rules or the operating body of general rules (Tao body) exists in all lives and things in a hidden integrative form. Everything contains Tao 0 or true me and is dominated by Tao body.

\subsection{Tao 0 Is Truth, and True Me Is Truth}

In the operating chart of general rules, Tao is 0 season, is not dominated by four-seasonal laws, is forever existence and is truth. "True me" in life body is corresponding to Tao 0 .

\subsection{Life Body Is the Integration of Truth with Falsehood}

Life body contains four grades of "me": true me, 
Yang me, Yin me and conscious me. True me is truth and Yang me, Yin me and conscious me are falsehood. Thus life body is the integration of truth and falsehood. In the operating chart of general rules, true me is the union of Tao 0 and false me 1, 2, 3 .

\subsection{One Body with Two Aspects of Universe General Rules}

According to Chart 1, the stillness and pureness extreme of the universe or Tao 0 is the body. The motion and contamination 1, 2, 3 is the use. Just as land is the silent mother, all living things are generated by land, which is the use of land. Land, the body, is stable and still. Living things are born in land and after they die they return to land. This is the same with the universe. The universe body is stable and still and is the universe sea [14]. Numerous galaxies are islands generated in the universe sea and after the four-seasonal circulation they return to the universe body.

The operating body of general rules is one body with two aspects, is the integration of true me 0 with false me 1, 2, 3 and is the integration and automatic operation of stillness with motion, union with division and upgrading with degrading. The operating body of general rules exists in all lives $(0,1,2,3)$ and things in the form of integration like Chart 1 . Thus Tao body is an integration containing $0,1,2$ and 3 . Tao body 0 is dominated by true me while Tao body 1, 2, 3 are dominated by false me. But they are all in the general rules.

4.6 The Operating Body of General Rules Dominated by True Me Is the Universe Body

True me is a permanent existence. Tao body 0 dominated by true me is nothing, is truth and is stillness and pureness extreme. It is everywhere and capable of everything. It has no birth or death and is permanent motion and existence. The birth and death of everything is the function of Tao body. Tao body 0 is the dominator of the universe and the body of the universe.

The body has no birth and death. It is not a substance phenomenon, nor spiritual phenomenon or natural phenomenon. Thus modern science has no way to exploring it. But humans can prove it through cultivating their morality. This is the reason why all religions in the world exist.

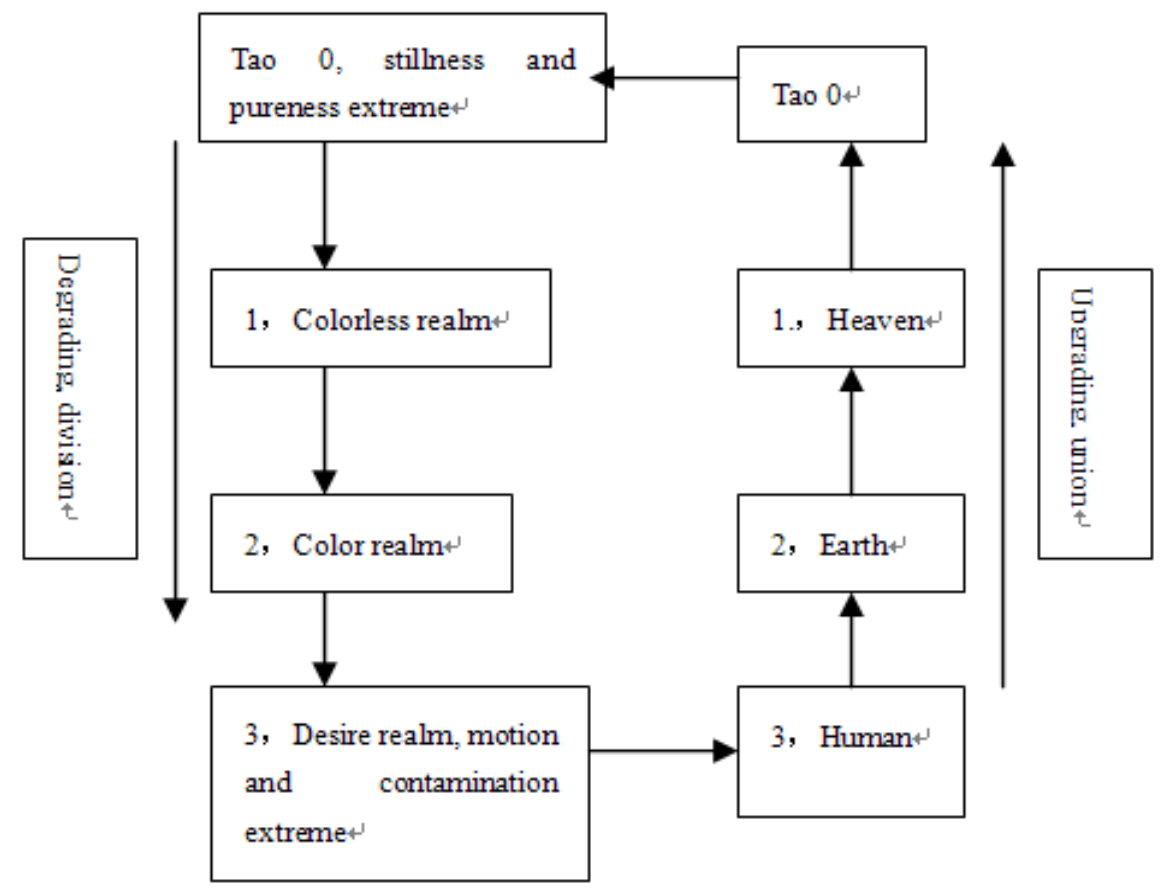

\section{Chart 1 Operating chart of general rules.}


4.7 The operating of general rules follows the middle course

The general rules contain true me and false me. True me is the major part and false me is the assistant part. False me is subject to true me. The general rules in false me are still impartial following the absolutely middle course. This is different from the human rules which always go to extremes.

\section{The Essential Features of the Universe Body}

Buddhism, Taoism and Confucianism have all proved the highest state of life is the body. Thus, we can find the essential features of the body in Buddhism, Taoism and Confucianism.

\subsection{Description for the Body in Taoism, Buddhism and Confucianism}

The universe body of Taoism is Tao body. According to Chart 1, Everything 1, 2, 3 comes from Tao 0 , so Tao 0 is the mother of everything, is the body of the universe and is the birthplace of all lives.

In Buddhism, the universe body is called nature. Huineng, the six master of Zen, said, after he realized the insight of Zen, that nature has five features: 1) be absolute pure without any stains; 2) exist permanently without birth or death; 3) contain the seeds for everything in the universe; 4) be able to generate everything in the universe; 5) have the King Kong body that never breaks [15].

In Confucianism, the universe body is called the great ultimate and the laws of changes are the laws of the universe [16].

\subsection{The Essential Features of the Body}

In Buddhism, the body has amazing features. As far as humans are concerned, the body has the following essential features.

1) The body is nothing

The body Tao 0 is nothing, namely the zero-dimension world. It has no substance, no spirit, no nature and no pollution. It is absolute silent and absolute free. It is big without edge and small without center. The body is endless in time and space.

2) The body is stable without any change and is a real changeless world

The body is permanently changeless so it is a real world. However, the one-dimension world, the two-dimension world and the three-dimension world where we live are changing constantly. So they are visional unreal world.

3) The body contains the seeds for everything in the universe

Although the body is not substance, nor spirit or nature, it can generate substance, spirit and nature. It can generate everything in the universe because it contains all the seeds for everything in the universe.

4) The body contains the laws for universe operation namely the laws for changes

The operating chart for general rules is the expressions of the laws for changes. The laws for changes are the origin of the general rules [16] and the laws for universe operation.

5) The body has the highest wisdom and energy of the universe

In the Pure School of Buddhism, the body is constant silent light, which is a permanently changeless and extremely pure high-energy life light body. It is the light of wisdom and spiral light [12]. The body can generate everything and can also destroy everything, including opening a quark confinement and form a quark confinement.

6) The body is super nothing and super everything, super virtual and super real, super soft and super rigid

Being super nothing and super everything means the body has the seeds of everything and can generate everything. The seeds exist in the form of nothing. Being super virtual and super real means the body is nothing but exists everywhere. Being super soft and super rigid means the body is so extremely soft and weak that it can enter everything but is as solid as 
King Kong that every tangible thing can rely on it.

7) The force of the body — King Kong force

The force of the body is zero-dimension life force [9]. The body is stable without any motion. It is the start point, destination and support of everything. Numerous giant galaxies are hanging in the universe body, forming orderly structures and motions. This means the force of the body is so vast that it can enter everything and make giant galaxies float [17]. According to the description for the body in Buddhism, the body can dominate everything but cannot be dominated by anything. Thus the force of the body is King Kong force.

The body contains all the secrets of the universe. Studying the body will surely lead to the solution of all the secrets in the universe.

\section{General Rule Evolution of Galaxies and Something from Nothing, Nothing from Something}

The general rules are the dominator of the universe. The universe and galaxies are not created by gods but rather the results of the operation of general rules. Galaxies are the functional unit of the universe and are rigid lives; they are the main representative of the operation of general rules and the start points of lives in all realms. During the evolution of galaxies, something generates from nothing and nothing generates from something.

\subsection{Eight States of Galaxies and the Original State of Galaxies}

From Chart 1, we can see galaxies have eight states: positive-going $0,1,2,3$ states and reverse-going 3, 2, 1,0 states. The 0 -state is the original state of galaxies. It is nothing and the vast blank space of the universe.

\subsection{The Original Galaxies Generate Motion from} Extreme Stillness and Something from Nothing

In the vast blank space of the universe, the original galaxies finally woke up from long sleep. This is the 0-state of life in galaxies, which has incredible huge power and wisdom and thus is the original state of general rules.

\subsection{Tao Generates One}

The original state of galaxies is thoughtless. When they woke up they began to have thoughts. Tao light 0 , the giant spiral light, turned into morality 1 to form giant whirlwind and invisible spiral galaxies. According to the evolution theory of the universe in Buddhism, the positive-going evolution order of galaxies is: body realm - colorless realm - color realm - desire realm [14]. The colorless realm is an intangible soul body without substance but with thought. That is to say, in this stage, no substance exists. In terms of space-time state [5], this state is a high-energy confinement intangible life body with the inside turning and transforming at a very high speed. This is corresponding to the quark confinement [5] of substances. Quark confinement is one, so this is Tao generating one of galaxies.

\subsection{One Generates Two}

After the formation of morality 1 confinement of the galaxies, part of the morality 1 power is transformed into tangible substances under the guidance of the general rules. That is to say, according to the requirements of life structures for substances, Tao light and morality power are transformed into fundamental particles in physics: neutrino, proton, electron and photon. Hydrogen is mainly tangible substance. Primitive nebulas and nebula plates then come into being. The process from intangible galaxies to tangible galaxies is to generate something from nothing.

The various substances known by modern science are basically formed by proton and photon. Only the particles with the longest life are the fundamental particles. The four kinds of particles in physics are neutrino, proton, electron and photon. They have the longest life among all particles so they are the 
fundamental particles. Other particles are either contained in them (like quark and gluon) or only appear when the four types of particles interact with each other, thus belonging to sub-level particles or secondary particles, not fundamental particles.

With the formation and constant increase of substances, they are absorbed into various gravitation centers in the galaxies and the centre temperature increases. When the temperature is high enough, nuclear fusion reaction happens and stars are formed. Light also appears in galaxies. Thus stars are two and the strong interaction of $\pi$ mesotrons [5]. This is one generating two and stars, the power mechanism, appear.

\subsection{Two Generates Three}

The planets surrounding the stars fail to raise their central temperature to the degree that makes nuclear fusion reaction happen, so more substances fall to the outer rings of the gravitation centers. When temperature is high, physical and chemical reactions happen and bond-force substances form, thus forming planets. This is two generating three. As the temperature continues to drop, the stable structures of the earth, namely, mantle, lithosphere, atmosphere and water circle, also form. They are the required conditions for living things to appear. The various living things appear in turn. The formation of planets symbolizes the formation of spiral galaxies with complex structure.

\subsection{The Reverse-Going Evolution of Galaxies}

Positive-going evolution is to transform Tao light and morality power into substances and generate something from nothing. Sometime after spiral galaxies - the most complex structure of galaxies form and stabilize, things begin to develop in the opposite direction and galaxies are bound to begin reverse evolution. Substances gradually turn into power, going through elliptical galaxies (bond-force substances turn into nuclear substances) and quasar (nuclear substances turn into protons and neutrons). At last, fundamental particles like quark confinement turn into Tao light, turning something into nothing. Galaxies finish one turn of evolution and form vast blank space. Chart 2 shows the operation of general rules of galaxies.

In Chart 2, when elliptical galaxies fail to turn into quasars, they will explode and enter a smaller evolution. Similarly, when the sun, the star in the Milky Way, fails to turn into a neutron star, it will turn into a red giant star, white dwarf star etc. When death

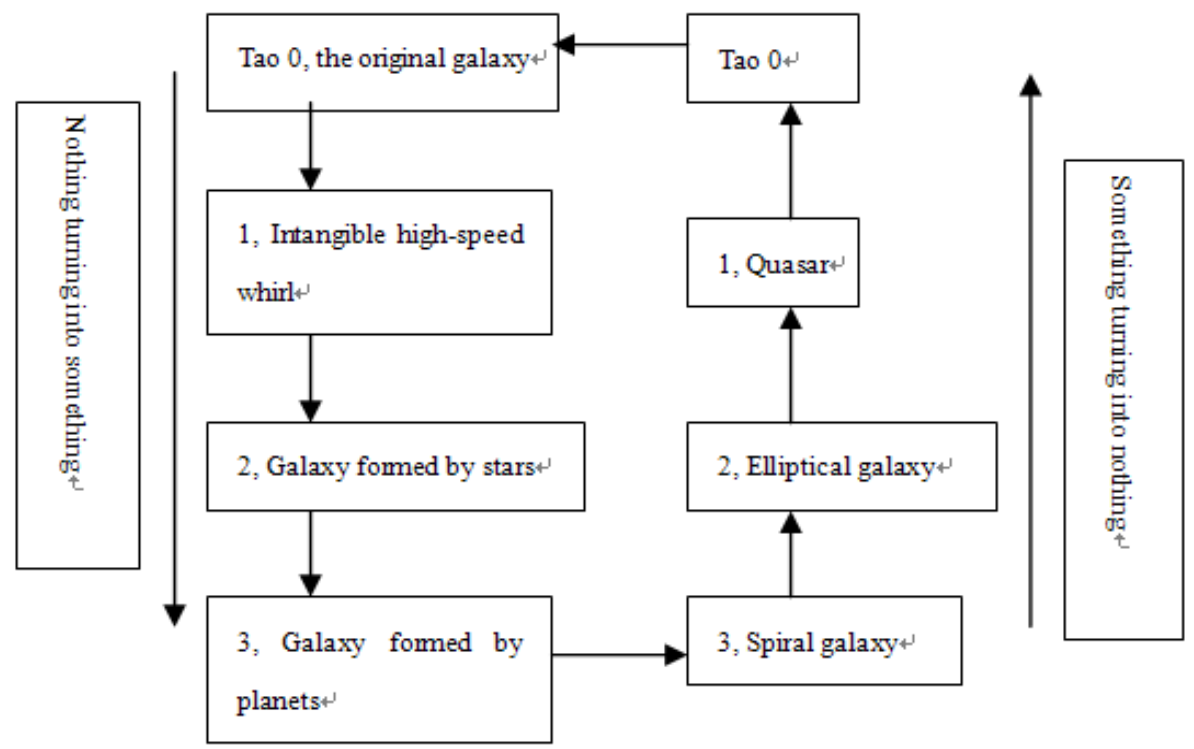

Chart 2 Operation of general rules of galaxies. 
comes, the smaller evolution begins.

Galaxies' positive-going evolution $0-1-2-3$ is from union to division. Galaxies' reverse evolution share the ideas of cultivating morality to return to general rules in Taoism, Buddhism, Confucianism and other religions, turning from division to union. Turning from nothing to something and from something to nothing in the evolution of galaxies is one of the incredible functions of the general rules.

\section{Motion-stillness (Birth-Death) Succession and Something-Nothing Inter-Promotion of the General Rules, the Reproduction Way of Life}

The operation of the general rules is presented in the four-seasonal movement of life or metabolism, which is a process of motion-stillness (birth-death) succession and something-nothing inter-promotion.

\subsection{Three Types of Metabolism in the Operation of General Rules}

According to the operation chart of general rules, the four-seasonal movement or metabolism of everything in the universe consists of three ways: 1) upgrading and degrading of things; 2) transverse four-seasonal movement of things; 3) longitudinal four-seasonal growth of things [9]. In the case of 1), zero generating one is something from nothing; one generating zero is nothing from something. During the process of operation of general rules of 0-1-2-3-2-1-0, state constantly changes with new things appearing constantly and old things disappearing constantly (transformation). This constant birth and death happen at the same time. The case of 2) is transverse four-seasonal movement. Spring and summer are birth while autumn and winter are death; birth and death happen at the same time. The case of 3) is the four-seasonal evolution of the whole life time of lives. In spring, lives are born; in summer, lives grow; in autumn, we gather; in winter, we collect. Spring and summer are Yang and birth while autumn and winter are Yin and death [18].

Metabolism is a continuous process of changes. In this process, the old do not die but turn into the new and the new turn into the old on appearing. The new are birth and the old are death. Like showing a film, metabolism is a four-seasonal process made of many continuous turning between birth and death.

\subsection{The Operation of General Rules Is} Motion-Stillness (Birth-Death) Succession and Something-Nothing Inter-Promotion

In the metabolism or four-seasonal movement of life, spring and summer are birth, motion and something while autumn and winter are death, stillness and nothing [18]. The continuous fourseasonal movement inside life is a process of motion-stillness succession, birth-death succession and something-nothing inter-promotion.

\subsection{The Reproduction Ways of Life}

Life reproduces in the four-seasonal movement to generate new life. The reproduction ways of life include self-generation, generation by augmentation and generation by transformation [6, 19]. Self-generation includes viviparity, humidogene and oviparity [11], which are all tangible reproduction. Generation by augmentation is internal reproduction, where the internal Yin and Yang copulate to generate intangible life like galaxy, the solar system and the earth. Internal intercourse generates intangible life so it is intangible reproduction. Generation by transformation is the transformation and appearing of heart. Transmigration in the six realms of existence is generation by transformation [11], which is a phenomenon that modern science has not known yet.

\section{The Reproduction of the Milky Way Galaxy-The Solar System-The Earth and Birth of Living Things}

Galaxies are where the general rules operate. The life realm, human society and man-made materials are 
all generated on the basis of galaxy life. Galaxies have internal reproduction systems. They evolve according to the general rules and generate all realms in order.

\subsection{The Milky Way Galaxy-The Solar System-The} Earth Have Internal Reproduction Systems

The Milky Way galaxy, the solar system and the earth are all inorganic life. They have Yin-Yang mechanism inside and thus have reproduction systems and reproduction abilities. Yang is father and Yin is mother. Yin and Yang are copulating all the time to generate everything in the universe. In the Book of Changes, "The heaven and the land copulate to generate everything" [16]. The morality cultivating in Taoism and Buddhism shows that everybody has an intangible reproduction system inside. The internal intangible couple copulates and produces intangible life - Dharmakaya. This process is the reflection of universe galaxy internal intangible Yin-Yang intercourse in the body of humans.

\subsection{The Milky Way Galaxy-The Solar System-The Earth Generate Different Forms of Life in Different States}

According to the general rules, the Milky Way galaxy evolves in the order of the original state, primitive nebula, the appearance of stars and the formation of planets, which is a gradual turning from the pure spiral light state into the most complex substance state galaxy. In this process, the Milky Way galaxy-the solar system-the earth go through different states or stages. The internal reproduction system also changes accordingly. The intercourse generates different life realms, which is shown in Table 3.

Life grades reflect the grades of power. According to Table 3, power constantly degrades from Buddhist, colorless realm, color realm to humans, animals and plants in desire realm, eukaryon lives and pronucleus lives. Different lives appear in order according to the grades of power. In the early days of the earth, Tao light and morality power were higher than now and the temperature was also higher. It was not suitable for organic lives to appear so there were only inorganic lives then. The inorganic life first appeared on the earth was inorganic humans and then inorganic animals, inorganic plants, inorganic eukaryon lives and inorganic pronucleus lives appeared in turn. When the temperature of the earth in the solar system reduced to the right degree for organic lives to appear, organic lives then appeared.

Organic lives: the appearance and existence of lives

Table 3 The Milky Way galaxy-the solar system-the earth generate different lives in different states.

\begin{tabular}{|l|l|l|}
\hline $\begin{array}{l}\text { State evolution of the Milky Way } \\
\text { galaxy }\end{array}$ & Ways of reproduction & Appearance of life realms \\
\hline Original galaxy & Generation by transformation & Buddhist, Immortals \\
\hline Morality 1 whirl & Internal intercourse of the Milky Way galaxy & Colorless realm \\
\hline Formation of stars & Internal intercourse of the Milky Way galaxy & Color realm \\
\hline Formation of planets & Internal intercourse of the Milky Way galaxy & Desire realm heaven \\
\hline Early stage of the solar system & Internal intercourse of the solar system & Inorganic humans with quality and form \\
\hline Middle stage of the solar system & Internal intercourse of the solar system & Inorganic animals with quality and form \\
\hline Early stage of the earth & Internal intercourse of the earth & Inorganic plants with quality and form \\
\hline & Internal intercourse of the earth & Inorganic eukaryon lives with quality and form \\
\hline & Internal intercourse of the earth & Inorganic pronucleus lives with quality and form \\
\hline Middle stage of the earth & Appearance of simple organic things & $\begin{array}{l}\text { Inorganic pronucleus lives turn into organic } \\
\text { pronucleus lives }\end{array}$ \\
\hline & Appearance of biological macromolecule & $\begin{array}{l}\text { Inorganic eukaryon lives turn into organic } \\
\text { eukaryon lives }\end{array}$ \\
\hline & $\begin{array}{l}\text { Appearance of complex biological } \\
\text { macromolecule }\end{array}$ & Inorganic plants turn into organic plants chains \\
\hline & Inorganic animals eat plants & Organic animal chain from \\
\hline & Inorganic humans eat plants and animals & Organic humans appear \\
\hline
\end{tabular}


are strictly restricted to temperature, whose range is very narrow. For example, the preference temperature range for plants is $0-35^{\circ} \mathrm{C}$. With the temperature of the earth in the solar system continuously dropping and the structure becoming more complex, organic life began to appear [20]. First, simple organics appeared when inorganic pronucleus lives turned into organic pronucleus lives. Then organic macromolecule appeared when inorganic eukaryon lives and plants turned into organic eukaryon lives and organic plants, and organic plants chains formed. As the morality power of inorganic animals was lower than that of inorganic humans, inorganic animals first ate plants and then turned into organic animals, forming animal biologic chains. With the internal power of the earth in the solar system continuously dropping and the temptation of the ecosphere to humans increasing, inorganic humans began to eat edible plants and animals, turning into organic humans. Over time, clans and countries of human society appeared and developed.

\subsection{New Lives Are Still Appearing on the Earth}

Thus, life on the earth was generated with the internal intercourse of the earth, the solar system and the Milky Way galaxy and the application of substances on the earth. This kind of internal intercourse still exists today, so new lives are still appearing on the earth. For example, some newly dug areas are bleak at first but after some time, new plants grow without anyone planting.

\section{Conclusions}

(1) Universe life includes the universe realm, the life realm, human society and man-made materials. All lives have four grades and are divided into rigid life, elastic life, tangible life and intangible life.

(2) There are four different types of "me" inside life bodies: true me, Yang me, Yin me and conscious me. True me never dies while Yang me, Yin me and conscious me all have birth and death. Substances also contain four types of me. The heart of lives is a system consisting of four grades (true heart, Yang me heart, Yin me heart and conscious heart). Life is a four-seasonal whole dominated by heart (true heart + fallacious heart).

(3) Things that can exist permanently and have no birth and death are truth. Things that have birth and death and are dominated by the four-seasonal rules are falseness. True me is truth while Yang me, Yin me and conscious me are falseness. The operating body of the general rules and the life body are the integration of truth and falseness. The operating body of general rules is a body with two aspects and the integration of true me 0 with false me $1,2,3$, the integration and automatic operation of stillness and motion, union and division, upgrading and degrading. The operating body dominated by true me is the universe body. The operation of the general rules always follows the middle course.

(4) The fundamental features of the universe body include: 1) the body is nothing; 2) it is absolutely pure without any pollution; 3 ) it has no birth or death and exists permanently; 4) it has the seeds for everything in the universe; 5) it can generate everything in the universe; 6) it is a King Kong body that never breaks; 7) the power of the body is King Kong force.

(5) The universe and galaxies are not created by gods but the results of the operation of the general rules. The movement of galaxies includes: positive-going movement $0-1-2-3$ and reverse-going movement 3-2-1-0. 0 state is the original state of galaxies and it is nothing and the giant blank area of the universe. Galaxies are something from nothing turning 0 state into 1 state. Turning from 1 state into 0 state is nothing from something.

(6) The operation of the general rules is presented as the four-seasonal movement of life, namely metabolism. It is a process of motion-stillness (birth-death) succession and something-nothing inter-promotion. The reproduction ways of life include self-generation, generation by augmentation and 
generation by transformation. Self-generation includes viviparity, humidogene and oviparity. Generation by augmentation is internal reproduction, namely generating intangible life through internal intercourse, which is intangible reproduction.

(7) The Milky Way galaxy, the solar system and the earth are inorganic lives with internal intangible reproduction system and reproduction ability. In the positive-going evolution of the Milky Way galaxy-the solar system-the earth, internal Tao power gradually decreases to go through different states and structures. The internal reproduction mechanism also changes accordingly and different life realms are generated through intercourse. Inorganic lives first appear on the earth: humans, animals, plants and bacteria. With the continuous dropping of temperature on the earth, organic lives then appear: bacteria, plants, animals and humans. New lives are still appearing on the earth.

\section{References}

[1] An anonymous author 2013. The Observation Notes by High-Level Qigong. Guilin: Guangxi Normal University Press, 12-430.

[2] Jinzhong Yan. 2014. "Beginning of A New Revolution of Science \& Technology.” Journal of Physical Science and Application 4 (4): 269-275.

[3] Jinzhong Yan January 2013. "Introduction to Unity of Physics and Biology, Inorganic Life Materials.” Journal of Physical Science and Application 3 (1): 58-64.

[4] Jinzhong Yan 1989. "Zero Space Theory." Qigong and Scence 6: 29.

[5] Jinzhong Yan 2013. "State Space-Time and Four States of the Universe." Journal of Physical Science and
Application 3 (2): 127-134.

[6] Jinzhong Yan 2015. "The Universal Grand Unified Theory Based on Life and Thought.” Journal of Physical Science and Application 5 (2): 147-157.

[7] Ontology world, 2019. https://baike.baidu.com /item/\%E6\%9C\%AC\%E4\%BD\%93\%E7\%95\%8C/45791 8 ?fr=Aladdin.

[8] Lao Zi 2011. De Tao Ching. Beijing: The International Cultural Publishing Company, 9-89.

[9] Jinzhong Yan 2016. "General Law of the Universe and Unity of All Universal Forces." Journal of Physical Science and Application 6: 21-28.

[10] [Ancient India] Sakyamuni Founder of Buddhism 2018. Shurangama Sutra. Beijing: Zhonghua Book Bureau, 15-20.

[11] Litian Fang 2006. Buddhist Philosophy. Changchun: Changchun Press, 126-194.

[12] Chunjin Xiong 2011. Tao Medicine. Beijing: Tuanjie Press, 1-130.

[13] Chunjin Xiong 2011. De Tao World. Beijing: China Yanshi Press, 60-69.

[14] [Ancient India] Sakyamuni Founder of Buddhism 2009. Avatamsaka sutr. Beijing: China Social Science Press, $1-63$.

[15] [Tang Dynasty] Hui Neng 2017. Altar Sutra. Beijing: Zhonghua Book Bureau, 21.

[16] Kong Zi 2012. The Book of Change. Beijing: The International Cultural Publishing Company, 209-225.

[17] Jingchun Meng, and Xinhua Wang 2002. The Inner Canon of Yellow Emperor. Shanghai: Shanghai Science and Technology Publishing House, 491.

[18] Yellow Emperor 2012. The Yellow Emperor Four Classics. Beijing: China Yanshi Press, 41-43.

[19] Chunjin Xiong 2011. Explication of Thought of Lao Zi's People Following the Earth. Beijing: Tuanjie Press, 121-266.

[20] Fengqi Men, and Xiangling Zhao 1984. Introduction to Paleontology. Beijing: Geological Press, 1-501. 